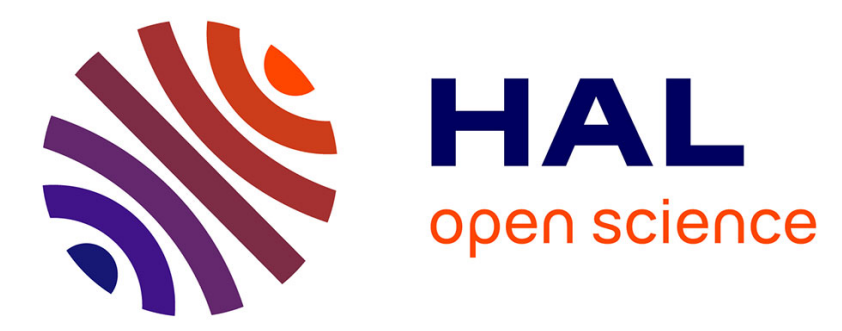

\title{
Relationship between coaches' health promotion activities, sports experience and health among adults
}

Aurélie van Hoye, Stacey Johnson, Susanna Geidne, Anne Vuillemin

\section{To cite this version:}

Aurélie van Hoye, Stacey Johnson, Susanna Geidne, Anne Vuillemin. Relationship between coaches' health promotion activities, sports experience and health among adults. Health Education Journal, 2020, 32 (9), pp.2435-2441. 10.1177/0017896920919777 . hal-02865898

\section{HAL Id: hal-02865898 \\ https://hal.univ-cotedazur.fr/hal-02865898}

Submitted on 14 Jul 2020

HAL is a multi-disciplinary open access archive for the deposit and dissemination of scientific research documents, whether they are published or not. The documents may come from teaching and research institutions in France or abroad, or from public or private research centers.
L'archive ouverte pluridisciplinaire HAL, est destinée au dépôt et à la diffusion de documents scientifiques de niveau recherche, publiés ou non, émanant des établissements d'enseignement et de recherche français ou étrangers, des laboratoires publics ou privés. 


\title{
Relationship between coaches' health promotion activities, sports experience and health among adults
}

Health Education Journal

$1-12$

(C) The Author(s) 2020

Article reuse guidelines: sagepub.com/journals-permissions DOI: $10.1177 / 0017896920919777$ journals.sagepub.com/home/hej

@SAGE

\author{
Aurélie Van Hoye ${ }^{a}$ id , Stacey Johnson ${ }^{b}$, \\ Susanna Geidne ${ }^{c}$ and Anne Vuillemin ${ }^{b}$ \\ ${ }^{a}$ APEMAC, University of Lorraine, Nancy, France \\ 'Laboratoire Motricité Humaine Expertise Sport Santé (LAMHESS), Université Côte d'Azur, Nice, France \\ 'School of Health Sciences, Faculty of Medicine and Health, Örebro University, Örebro, Sweden
}

\begin{abstract}
Objective: Health promotion in sports clubs is receiving increased attention, but its benefits have not been widely evaluated for two reasons: (I) the difficulty in measuring ecological approach outcomes and (2) the existing literature having focused more on coaches' efficiency rather than on health promotion. This article analyses the relationship between coaches' health promotion activities, sports experience and health among adult sports participants.

Design: A cross-sectional study using self-reported measurement among 204 adult sports participants $\left(M_{\text {age }}=49.05\right)$. A questionnaire measuring demographics, coaches' health promotion activities (healthy lifestyle, substance use and respect for oneself and others), sports experience (enjoyment, subjective vitality) and health (perceived health and quality of life, self-esteem) was completed either before or after a training session.
\end{abstract}

Setting: Sixteen sports clubs in France

Method: Multilevel analyses were used to evaluate the relationships between health promotion, sports experience and health outcomes, while $t$-tests compared differences between male adult and youth samples. Results: Adult perceptions of coaches' health promotion activities were linked to enjoyment, perceived health and subjective vitality. The topic 'healthy lifestyle' was related to enjoyment and perceived health among adults. The topic 'respect for oneself and others' was related to self-esteem.

Conclusion: Adult and youth perceptions of coaches' health promotion activities vary and are linked to different health outcomes. More research is needed to better identify the benefits of health promotion in sports clubs for sports participants, including longitudinal studies to explore causal relationships between variables.

\section{Keywords}

Coaches, health, health promotion, multilevel analysis, sports clubs, sports experience 


\section{Introduction}

Building on the Ottawa Charter (World Health Organization [WHO], 1986), the WHO has defined health promotion as 'the process of enabling people to increase control over and to improve their health', which has encouraged the use of settings as places for health promotion planning and action. While this approach has been largely implemented in contexts such as schools (Lee et al., 2003) or universities (Dooris et al., 2014), non-traditional settings, such as sports clubs, have only recently been targeted (Kokko et al., 2014). Sports clubs may be defined as organisations 'having in common the provision of opportunities for competition and sports practice, while some can also be considered social organisations, promoting social welfare and health' (Donaldson and Finch, 2012: 4). Sports clubs are important settings from a public health perspective, for several reasons. First, they target a large and broadly diverse population, cutting across socioeconomic status and lifespan (Eime et al., 2013). Second, the voluntary nature of sports participation may support members' receptiveness to health information (Kokko et al., 2015a). Moreover, previous work has shown the benefits of promoting health in sports clubs, such as increased membership (Meganck et al., 2015) or higher motivation for coaches to continue coaching (Van Hoye et al., 2015).

In the last decade, the literature has principally focused on identifying the benefits of sports participation and/or physical activity, showing that sports clubs can contribute to physical activity (Van Hoye et al., 2013) and also to sports participants' social, mental and physical health (Eime et al., 2013; Oja et al., 2015). In an effort to go beyond sports or physical activity provision, multiple authors (Geidne et al., 2019; Kokko et al., 2015b), as well as the European Commission's (2007) White Paper on Sport, have argued that sports have the potential to develop health promotion, which could lead to even better sports experiences and health (Van Hoye et al., 2016). In France specifically, policy makers launched the Plan Sport Santé Bien-être (Sport, Health and Well-being) (Honta, 2016) to better link sports and public health.

Studies have focused on the theoretical aspects of health-promoting sports clubs (Geidne et al., 2019; Kokko et al., 2014) or on how the board of directors can improve health promotion (Casey et al., 2009, 2012b; Meganck et al., 2015), but much less is known about the implications and benefits of coaches' health promotion activities. Previous work (Quested et al., 2013) has supported the assumption that coaches' behaviours are related to variability in participants' sports experiences. In other words, research has shown that coaches' behaviour may predict sports participants' emotional, cognitive and behavioural outcomes (Quested et al., 2013). To our knowledge, the existing literature has focused principally on the coach-athlete interaction, especially on coaches' efficiency and performance, but less on directly encouraging health promotion, which encompasses social, physical and mental health.

Only one study to date (Van Hoye et al., 2016) has reported the benefits of coaches' health promotion activities on youth participants' sports experiences and health. The results of this study showed a relationship between coaches' health promotion activities and positive sports experience (greater enjoyment and fewer drop-out intentions) and a higher quality of life among young male football players in France (Van Hoye et al., 2016). Two studies, however, have compared coaches' and participants' perceptions of coaches' health promotion activities among youth participants (Kokko et al., 2015a; Van Hoye et al., 2018). Results have shown that youth coaches principally promote greater 'respect for one-self and others', compared to 'healthy lifestyles' and 'substance abuse' (Kokko et al., 2015a; Van Hoye et al., 2018).

In addition, the difficulty in identifying the outcomes of health promotion approaches has been broadly discussed (Dooris, 2006). In principle, health promotion activities should theoretically impact health in a holistic manner, producing physical, social and mental health benefits (WHO, 1986). However, the number of determinants of health and their interactions makes it difficult to 
identify the path between coaches' health promotion activities and sports participants' outcomes (Dooris et al., 2014). To our knowledge, no previous study has undertaken this work. As a result, we decided to investigate selected health outcomes of a positive motivational climate on social health. Variables measured in previous European studies (Duda et al., 2013) were chosen, including those that described positive motivational experiences (subjective vitality and enjoyment), as well as variables used to evaluate health in general population surveys (self-reported health, quality of life and self-esteem) (Currie et al., 2009).

To provide more evidence and a rationale for lobbying to policy makers on the public health benefits of health promotion in sports clubs, especially on how coaches' behaviours are linked to adult sports participants' experience and health, this study expands on a previous youth sports publication (Van Hoye et al., 2016). As relationships to health and to sports experiences vary across the lifespan (Allender et al., 2006), such studies are needed to understand how to improve coaches' health promotion behaviours from sports participants' perspectives. In addition, our work sought to compare youth and adult perceptions of coaches' health promotion activities to help identify approaches attuned to specific characteristics of the targeted population, either adults or youth. More specifically, the aims of the study were to (1) analyse the relationship between adult sports participants' perceptions of coaches' health promotion activities and sports experiences (subjective vitality and enjoyment), as well as health (perceived health, perceived quality of life and selfesteem) and (2) compare youth and adult sports participants' scores of perceptions of coaches' health promotion activities using a sample from a previously published study (Van Hoye et al., 2016).

\section{Materials and methods}

\section{Data collection and procedures}

Data were collected in Lorraine, North-East France, from 16 sports clubs that agreed to participate in the study (39\% of contacted clubs). A total of 204 participants, on average 13 participants $(\geqslant 8)$ per club, took part in the study. Half of the participants were women (49.5\%). Their ages ranged between 18 and 82 years, with an average of 46.08 years (standard deviation $[S D]=18.59$ ). On average, sports experience was 12.47 years $(S D=12.12)$. Among participants, $43 \%$ also volunteered within their sports club.

The sample included 38\% team sports participants (soccer, volleyball, water polo, handball) and $62 \%$ individual sports participants (gymnastics, badminton, tennis, fencing, pilates). The study was registered with the CNIL (Commission Nationale de l'Informatique et des Libertés) and approved by the Agence Régionale de Santé Grand Est (Regional health Agency Grand Est) and the Direction départementale de la cohésion sociale (Departmental Directorate of Social Cohesion). Sports club presidents and/or secretaries were contacted to request agreement to participate in the study. Once agreement had been obtained, trained researchers travelled to the clubs before or after training or practice events to ask sports participants to complete a questionnaire. Data collection took place mid-season (January-March 2018). Each participant was required to provide written informed consent before inclusion, and participants were allowed to withdraw at any time, without consequence.

\section{Instruments}

The questionnaire assessed demographics (age, gender, type of sports, experience in sports and volunteering in sports clubs), enjoyment, subjective vitality, self-esteem, self-reported quality of 
life and self-reported health. Participants were also asked to rate how they perceived their coaches' health promotion activities using the Coach Health Promotion Activities Scale (CHPAS) (Van Hoye et al., 2016, 2018).

The CHPAS (Van Hoye et al., 2016) has been used to measure sports participants' perceptions of coaches' health promotion activities. The questionnaire includes three topics: 'substance use', 'respect for oneself and others' and 'healthy lifestyle'. Sports participants were asked to rate coaches' health promotion activities (e.g. 'To what extent, in your opinion, did your coach emphasise health promotion topics during the last month?') on a 5-point scale ranging from 1 (does not describe my coach at all) to 5 (describes my coach very well). The higher the score, the higher the perceived involvement of coaches in the item or the topic. The scale has been validated among youth sports participants in previous work (Van Hoye et al., 2016, 2018). Reliability analysis showed good internal consistency for the general score $(\alpha=.88)$, substance use $(\alpha=.84)$, respect for oneself and others $(\alpha=.80)$ and healthy lifestyle $(\alpha=.82)$.

The enjoyment subscale from the Intrinsic Motivation Inventory (McAuley et al., 1989) assessed the degree of sports participants' enjoyment while practising sport during the last month. Participants answered four items (e.g. I enjoyed the activities in my sports) on a 5-point Likert-type scale ranging from 1 (do not agree at all) to 5 (completely agree), with a high score representing high enjoyment in sports practice. The scale has shown good internal consistency $(\alpha=.88)$.

Subjective vitality was assessed by the Subjective Vitality Scale (Ryan and Frederick, 1997), which included five items (e.g. 'I felt full of vitality'). Sports participants were asked to describe how they felt during the last month in their daily life. Ratings were based on a 5-point Likert-type scale ranging from 1 (do not agree at all) to 5 (completely agree), with a high score representing high subjective vitality. Internal consistency for this scale was good $(\alpha=.90)$. Both enjoyment and subjective vitality measures have been used in a previous study among youth football players as measures of positive sports experience (Duda et al., 2013).

Perceived health was measured via a single item: 'Would you say your health is: (1) excellent; (2) good; (3) fair; (4) poor'. Perceived quality of life was also assessed through a single item (Cantril, 1965), with participants rating their 'perceived worst' to their 'perceived best' life on a 10 -point scale. Both indicators have been used extensively in public health research (Benjamins et al., 2004) as well as in a youth soccer player sample (Wold et al., 2013).

Global self-esteem was assessed by the Short Version of the Physical Self-Description Questionnaire (Marsh et al., 2010), a 4-item questionnaire which demonstrated acceptable internal consistency (with this sample, $\alpha=.79$ ). Sports participants used a 5-point Likert-type scale ranging from 1 (do not agree at all) to 5 (completely agree), with higher scores demonstrating higher selfesteem. Two items were reversed to obtain the mean score. The three health measures (perceived health and quality of life, as well as self-esteem) are variables often measured in data collection on youth health behaviours and have been previously used in a youth football sample (Wold et al., 2013).

\section{Data analysis}

After preliminary screening and treatment of missing data, descriptive analysis and cofounder influence on the results were tested using univariate analysis of variance (ANOVA) and multivariate analysis of variance (MANOVA). Multilevel modelling, using Predictive Analytics Software version 21 , was used to control for club variability (level 2). Intra-class correlations (ICCs) were calculated to estimate how much clubs contributed to the variance in each sports experience and health variable, using a completely unconditional two-level hierarchical model accounting for club variance. The proportion of total variance in the dependent variables attributed to sports clubs was 
$5 \%$ for enjoyment, $1 \%$ for subjective vitality, $16 \%$ for perceived health, $1 \%$ for life quality and $3 \%$ for self-esteem. To reveal within-sports-club agreement, ICCs were calculated in each club for the global health promotion score and for the three topics: respect for oneself and others, healthy lifestyle and substance use. To test the relationship between coaches' health promotion activities and sports experience and health, two models were compared. The first was our unconditional model and the second included the global score for health promotion or its three component topics. A significant improvement of the fit statistic was calculated by the level of deviance statistic of the model (i.e. $-2 \log \mathrm{L} / \mathrm{df}$ ), which follows a $\kappa^{2}$ distribution at $k$ degrees of freedom ( $k$ representing the number of added parameters to estimate). A significant $\kappa^{2}$ at $p<.05$ indicates a greater improvement in the fit statistic compared to the previous model (Rasbash et al., 2000). To compare the data with previous results among a sample collected during a French study of male youth football players (Van Hoye et al., 2016), $t$-tests between the two samples were used.

\section{Results}

\section{Preliminary analysis}

A verification of the assumption of multivariate analysis (Tabachnick and Fidell, 2007) confirmed that the conditions of normality (skewness ranging from -0.60 to 1.05 and kurtosis from -0.83 to 0.83 ; except a high kurtosis for self-esteem with 2.16), linearity, homogeneity of variance, homoscedasticity and independence were all met. Data were missing at random (up to 10\%), as determined by a non-significant Little's MCAR (Missing Completely At Random) test $(p=1.00)$. List-wise deletion (i.e. deletion of an individual if data were missing) was undertaken. A one-way MANOVA with the club as an independent variable and sports participants' demographic variables (age, experience) as dependent variables found no significant differences between clubs, Wilks' $\lambda=.46, F(2,146)=0.82, p>.05$. These variables were therefore not added to the multilevel model.

\section{Descriptive statistics}

In general, sports participants' perceptions of coaches' health promotion activities averaged 2.96 $(S D=0.88)$, acknowledging first 'respect for oneself and others' $(M=3.37 ; S D=1.04)$, before 'healthy lifestyle' $(M=3.21 ; S D=1.05)$ and 'substance use' $(M=2.08 ; S D=1.14)$ (see Table 1 for details). Post hoc least significant difference (LSD) tests indicated significant differences between the three topics $(p<.02)$. With respect to gender, a one-way ANOVA with gender as an independent variable and coaches' health promotion scores as a dependent variable showed a significant difference, $F(1,202)=17.00, p<.001$. Men $(M=3.20 ; S D=0.88)$ had a higher perception of coaches' health promotion activities than women $(M=2.71 ; S D=0.81)$. A significant difference was also found for health promotion topics, Wilks' $\lambda=.91, F(3,200)=6.39, p<.001$, with respect to gender. No differences were found for sports experience and age on health promotion. A significant difference was found, however, for the type of sports, $F(1,188)=11.76, p<.01$, with individual sports $(M=2.76 ; S D=0.87)$ having lower health promotion scores compared to collective sports $(M=3.19 ; S D=0.79)$. A significant difference was also found for the three topics, Wilks' $\lambda=.87, F(3,186)=9.26, p<.001$, when taking type of sports into consideration. Volunteering at the sports club also played a role in the perception of coaches' health promotion scores, $F(1,187)=3.99, p<.05$. Sports participants who volunteered had higher scores $(M=3.08$; $S D=0.80)$ compared to those who $\operatorname{did} \operatorname{not}(M=2.84 ; S D=0.87)$. In a multivariate variance analysis, with volunteering as an independent variable and the three topics as dependent variables, 
Table I. Descriptive results.

\begin{tabular}{|c|c|c|c|c|c|c|c|c|}
\hline & \multicolumn{2}{|c|}{ HP score } & \multicolumn{2}{|c|}{ Substance use } & \multicolumn{2}{|c|}{$\begin{array}{l}\text { Respect for oneself and } \\
\text { others }\end{array}$} & \multicolumn{2}{|c|}{$\begin{array}{l}\text { Healthy } \\
\text { lifestyle }\end{array}$} \\
\hline & $M$ & $S D$ & $M$ & $S D$ & $M$ & $S D$ & $M$ & $S D$ \\
\hline \multicolumn{9}{|l|}{ Gender } \\
\hline Male & 3.20 & 0.88 & 2.29 & 1.26 & 3.66 & 0.96 & 3.42 & 1.01 \\
\hline Female & 2.71 & 0.81 & 1.86 & 0.97 & 3.08 & 1.05 & 2.99 & 0.98 \\
\hline \multicolumn{9}{|l|}{ Volunteering } \\
\hline Yes & 3.08 & 0.80 & 2.11 & 1.07 & 3.56 & 0.95 & 3.34 & 1.05 \\
\hline No & 2.84 & 0.87 & 1.97 & 1.12 & 3.21 & 1.06 & 3.11 & 1.05 \\
\hline \multicolumn{9}{|l|}{ Type of sports } \\
\hline Individual & 2.76 & 0.77 & 1.87 & 0.98 & 3.12 & 0.09 & 3.08 & 0.97 \\
\hline Collective & 3.19 & 0.79 & 2.25 & 0.12 & 3.83 & 0.11 & 3.26 & 0.12 \\
\hline Total & 2.96 & 0.88 & 2.08 & 1.14 & 3.37 & 1.04 & 3.21 & 1.05 \\
\hline
\end{tabular}

HP: health promotion; SD: standard deviation.

non-significant results were found. Only univariate results showed a significant difference for 'respect of oneself and others' $F(1,187)=5.37, p<.05$, with volunteers having higher scores $(M=3.56 ; S D=0.95)$ compared to non-volunteers $(M=3.21 ; S D=1.06)$.

A significant difference was found between clubs for the health promotion activities, $F(1,188)=4.18, p<.001$, and for the three topics, Wilks' $\lambda=.48, F(3,186)=3.37, p<.001$. ICCs were calculated for each club to compare participants' perceptions of the three topics and to analyse the consistency of their perceptions, varying from acceptable to very good $\left(M_{\mathrm{ICC}}=0.82\right.$, ranging from 0.67 to 0.94 ).

\section{Relationship between coaches' health promotion activities and sports experience and health}

Looking at the model of enjoyment (see Table 2 for details), the addition of the general health promotion score showed a significant decrease $(p<.05)$ of the deviance statistic of the model $(\Delta=4.46)$. The general health promotion score was significantly related to sports participants' enjoyment $(\beta=0.92, p<.05)$. In a second model, the addition of the three topics did not significantly decrease the deviance statistic of the model. Moreover, the addition of the general health promotion score did not significantly decrease the deviance statistic of the model for perceived quality of life, but the addition of the three topics did significantly reduce the deviance $(\Delta=13.80$, $p<.01)$. Respect for oneself and others $(\beta=-0.31, p<.05)$ and healthy lifestyle $(\beta=0.31, p<.05)$ were significantly related to quality of life. The addition of the general health promotion score did not significantly decrease the deviance statistic of the model of self-esteem, but by adding the three topics, the deviance statistic was significantly reduced $(\Delta=8.75, p<.05)$. Respect for oneself and others $(\beta=0.16, p<.01)$ was significantly related to self-esteem. The addition of the general health promotion score showed a significant decrease $(p<.001)$ of the deviance statistic of the model of subjective vitality $(\Delta=12.55)$. The general health promotion score was significantly related to sports participants' subjective vitality $(\beta=0.35, p<.001)$. When analysed a second time, the addition of the three topics significantly reduced the deviance statistic $(\Delta=15.22, p<.05)$. Substance use $(\beta=0.19, p<.05)$ was significantly related to subjective vitality. The addition of the general health promotion score showed a significant decrease $(p<.05)$ in the deviance statistic of the 
Table 2. Results of the multilevel model for prediction of adult sports participants' experience and health.

\begin{tabular}{|c|c|c|c|c|c|c|}
\hline & \multicolumn{2}{|l|}{ Model I* } & \multicolumn{2}{|l|}{ Model HP } & \multicolumn{2}{|c|}{ Model topics } \\
\hline & Estimate & $S E$ & Estimate & $S E$ & Estimate & $S E$ \\
\hline \multicolumn{7}{|l|}{ Enjoyment } \\
\hline$-2 \log L$ & 305.98 & & 301.52 & & 299.21 & \\
\hline Intercept & $4.28 * * *$ & 0.51 & $4.01 * * *$ & 1.36 & $3.97 * * *$ & 0.14 \\
\hline $\mathrm{HP}$ & & & $0.92 *$ & 0.04 & & \\
\hline Substance use & & & & & -0.01 & 0.03 \\
\hline Respect for oneself and others & & & & & 0.01 & 0.04 \\
\hline Healthy lifestyle & & & & & $0.1 *$ & 0.04 \\
\hline \multicolumn{7}{|l|}{ Subjective vitality } \\
\hline$-2 \log L$ & 667.96 & & 655.43 & & 652.74 & \\
\hline Intercept & $4.46 * * *$ & 0.08 & $3.39 * * *$ & 0.31 & $3.49 * * *$ & 0.32 \\
\hline $\mathrm{HP}$ & & & $0.36 * * *$ & 0.01 & & \\
\hline Substance use & & & & & $0.19 *$ & 0.09 \\
\hline Respect for oneself and others & & & & & -0.06 & 0.09 \\
\hline Healthy lifestyle & & & & & 0.19 & 0.10 \\
\hline \multicolumn{7}{|l|}{ Quality of life } \\
\hline$-2 \log L$ & 765.80 & & 763.05 & & 751.99 & \\
\hline Intercept & $7.14^{* * *}$ & 0.12 & $6.49 * * *$ & 0.40 & $6.79 * * *$ & 0.42 \\
\hline HP & & & 0.21 & 0.12 & & \\
\hline Substance use & & & & & 0.20 & 0.11 \\
\hline Respect for oneself and others & & & & & $-0.31 *$ & 0.12 \\
\hline Healthy lifestyle & & & & & $0.31 *$ & 0.13 \\
\hline \multicolumn{7}{|l|}{ Self-esteem } \\
\hline$-2 \log L$ & 414.47 & & 414.15 & & 405.72 & \\
\hline Intercept & $3.91 * * *$ & 0.06 & $4.00 * * *$ & 0.17 & 4.16*** & 0.18 \\
\hline $\mathrm{HP}$ & & & -0.03 & 0.05 & & \\
\hline Substance use & & & & & 0.06 & 0.05 \\
\hline Respect for oneself and others & & & & & $0.16 * *$ & 0.05 \\
\hline Healthy lifestyle & & & & & 0.05 & 0.05 \\
\hline \multicolumn{7}{|l|}{ Perceived health } \\
\hline$-2 \log L$ & 322.98 & & 319.04 & & 314.22 & \\
\hline Intercept & $2.10^{* * *}$ & 0.06 & $2.36 * * *$ & 0.14 & $2.45 * * *$ & 0.15 \\
\hline $\mathrm{HP}$ & & & $-0.09 *$ & 0.4 & & \\
\hline Substance use & & & & & 0.04 & 0.04 \\
\hline Respect for oneself and others & & & & & -0.01 & 0.04 \\
\hline Healthy lifestyle & & & & & $-0.12^{* *}$ & 0.04 \\
\hline
\end{tabular}

HP: health promotion; SE: standard error.

Model I = model with control variables as fixed effect, club as random effect.

$* p<.05 ; * * p<.01 ; * * * p<.001$.

model of perceived health $(\Delta=3.94)$. The health promotion general score was significantly related to sports participants' perceived health $(\beta=-0.09, p<.001)$. During the second analysis, the addition of the three topics significantly reduced the deviance statistic $(\Delta=8.76, p<.05)$, and healthy lifestyle $(\beta=-0.12, p<.01)$ was significantly related to perceived health. 
Table 3. Comparison of youth and adult health promotion scores.

\begin{tabular}{|c|c|c|c|c|c|}
\hline & \multicolumn{2}{|c|}{ Adult score } & \multicolumn{2}{|c|}{ Youth score } & \multirow[t]{2}{*}{ Difference } \\
\hline & $M$ & $S D$ & $M$ & $S D$ & \\
\hline Health promotion & 3.20 & 0.87 & 3.44 & 0.76 & $-0.24 * *$ \\
\hline Substance use & 2.28 & 1.26 & 2.49 & 1.38 & -0.21 \\
\hline Respect for oneself and others & 3.66 & 0.95 & 4.00 & 0.81 & $-0.34 * * *$ \\
\hline Healthy lifestyle & 3.42 & 1.09 & 3.58 & 0.94 & -0.16 \\
\hline
\end{tabular}

$S D$ : standard deviation.

$* p<.05 ; * * p<.01 ; * * p<.001$.

\section{Comparison between youth and adult perceptions of coaches' health promotion activities}

The youth sample from a previous French study (Van Hoye et al., 2016) was compared to our adult sample. To be able to compare youth and adult scores, female data were removed for two reasons: (1) low female representation in the youth sample and (2) gender as a confounder in the adult sample. The youth sample was not gender balanced; only $5 \%$ of the sample was women, which is similar to French participation rates in football. Moreover, as described earlier, gender seemed to play a role in perceptions of coaches' health promotion activities within the adult sample. Comparisons of male scores (103 adults and 333 youth with a mean age of 11.20 years) showed a significant difference in the general health promotion score, $F(1,443)=7.21, p<.01$. In relation to the three topics, only 'respect for oneself and others' showed a significant difference, $F(1,443)=12.90, p<.001$, between youth and adult scores (see Table 3 for details). Adult scores were lower than youth scores for each topic.

\section{Discussion}

Sports clubs are increasingly recognised as health-promoting settings by researchers (Geidne et al., 2019) as well as policy makers (European Commission, 2007), but evidence on the benefits of such an approach on sports participants is limited, especially among adults and in different sports (Geidne et al., 2019). This study analysed the relationship between coaches' health promotion activities among adults and their sports experience and health, and then compared these results to those from a sample of youth football players (Van Hoye et al., 2016).

To date, descriptive results regarding the three health promotion topics have shown similar patterns within different samples (Kokko et al., 2015b; Van Hoye et al., 2016), with 'respect for oneself and others' ranking first, followed by 'healthy lifestyle' and 'substance use'. These results reinforce the idea of there being agreement about the priorities of sports clubs in regard to health promotion, focusing first on social health and then on behavioural health and addictions in both France and Finland (Kokko et al., 2015b; Van Hoye et al., 2018). These results are also consistent with previous studies found at the coaching level, leading us to think that actors within sports clubs agree on such health promotion activities in France and Finland (Kokko et al., 2009; Van Hoye et al., 2018). They should encourage policy makers to focus more on healthy lifestyle promotion and substance use prevention, as a complement to the social aspects of sports, which seemed to be well provided for within these nations' sports clubs (Meganck et al., 2015).

Results have shown that gender, type of sports and volunteering were related to adult sports participants' perceptions of coaches' health promotion activities, whereas age and sports experience were not related to these perceptions. These results also confirm the findings of a previous 
study, showing gender played a role in coaches' health promotion perceptions (Van Hoye et al., 2015 ) - men having higher perceptions than women. The difference in regard to the type of sports participated in contrasts with previous work (Kokko et al., 2009). This could be due to the classification undertaken by researchers to calculate the difference, but needs to be further investigated in future work. Finally, in this work, being a volunteer at the club seemed to increase the perception of coaches' health promotion activities. One hypothesis in regard to this result is that volunteering increases awareness, but also a sense of belonging to the sports club, which are both ingredients of successful health promotion activities (Kokko, 2014a).

Coaches' general health promotion score was related to enjoyment, perceived health and subjective vitality of adult sports participants, confirming former youth results (Van Hoye et al., 2016). These results help strengthen the belief that coaches' health promotion activities provide added value to sports club activities to broaden the benefits of sports participation in organised settings (Eime et al., 2013) and support the role sports clubs and especially coaches can play in public health (Mansfield et al., 2018; Misener and Misener, 2016). The topic 'healthy lifestyle' was significantly related to enjoyment and perceived health among adults. The topic 'respect for oneself and others' was significantly related to self-esteem. Such results may point to a difference between reasons for engagement in sports, whereby young people do so for enjoyment, fun and development, while adults engage for health reasons (Allender et al., 2006). The topic 'Substance use' did not predict any outcome. While this result was not surprising among youth, it was expected that sports clubs could raise adult awareness on substance use (Casey et al., 2012a).

Despite similar patterns, a significant difference was found between youth and adult general health promotion scores and the score for respect for oneself and others. These results are consistent with those of a coaching study in Flanders, showing that youth coaches perceived a higher 'fair play' (88\%) and 'everyone plays' ideology compared to coaches for adults (64\%) (Meganck et al., 2016). Differentiating between these two populations is important, because their reasons for sports involvement are often distinct (Allender et al., 2006) and could explain this difference.

\section{Limitations}

Findings in this study are based on self-report, which is sensitive to social desirability bias (Van de Mortel, 2008). Moreover, some coaches' health promotion activities may not have been reported by sports participants, as they may have been considered usual coaching activities without awareness of their health-promoting connotations. This study was also cross-sectional in nature, meaning that the direction of the relationship has been theoretically identified, but a reverse relationship could also exist, for example, if you have a positive sports experience and good health, you may be more likely to better perceive coaches' health promotion activities. Moreover, while the adult sample is more diverse than in previous work (Geidne et al., 2019), studies on a broader range of sports are needed to ensure the validity of the results. Finally, the health outcomes attributable to settingsbased approaches are numerous and diverse (Dooris, 2006), ranging from physical to social, mental and psychological health. Other variables, such as health behaviour, inclusion, equality and moral attitudes, should also be tested in relation to health promotion.

\section{Conclusion}

This work adds empirical findings on the outcomes of coaches' health promotion activities across the lifespan, reinforcing the rationale that these activities are beneficial not only to youth but also to adult sports experiences and health. Moreover, these results emphasise the role sports clubs can play in public health (Honta, 2016), not only by increasing physical activity (Kokko et al., 2019) 
but also by embracing the settings-based approach (Kokko, 2014b) to consider sports participants' health in a holistic way (Geidne et al., 2019; Johnson et al., 2019). As this research demonstrated, coaches' health promotion activities should be tailored to participant age, gender and type of sports in order to produce the greatest perceived benefits.

\section{Acknowledgements}

We acknowledge the Agence Régionale de Santé Grand Est (Regional health Agency Grand Est) and the Direction départementale de la cohésion sociale (Departmental Directorate of Social Cohesion), as well as the Contrat local de santé (local health contract) of Val de Lorraine.

\section{Funding}

The author(s) disclosed receipt of the following financial support for the research, authorship and/or publication of this article: This work was supported by the French Institute of Sweden (TOR mobility program 2019).

\section{ORCID iD}

Aurélie Van Hoye (iD https://orcid.org/0000-0002-0495-4747

\section{References}

Allender S, Cowburn G and Foster C (2006) Understanding participation in sport and physical activity among children and adults: A review of qualitative studies. Health Education Research 21: 826-835.

Benjamins MR, Hummer RA, Eberstein IW, et al. (2004) Self-reported health and adult mortality risk: An analysis of cause-specific mortality. Social Sciences and Medicine 59: 1297-1306.

Cantril H (1965) The Pattern of Human Concerns. New Brunswick, NJ: Rutgers University Press.

Casey M, Harvey J, Eime R, et al. (2012a) Examining changes in the organisational capacity and sport-related health promotion policies and practices of State Sporting Organizations. Annals of Leisure Research 15: 261-276.

Casey MM, Payne WR and Eime RM (2012b) Organisational readiness and capacity building strategies of sporting organisations to promote health. Sport Management Review 15: 109-124.

Casey MM, Payne WR, Brown SJ, et al. (2009) Engaging community sport and recreation organisations in population health interventions: Factors affecting the formation, implementation, and institutionalisation of partnerships efforts. Annals of Leisure Research 12: 129-147.

Currie C, Gabhainn SN, Godeau E, et al. (2009) The Health Behaviour in School-aged Children: WHO Collaborative Cross-National (HBSC) study: Origins, concept, history and development 1982-2008. International Journal of Public Health 54: 131-139.

Donaldson A and Finch CF (2012) Sport as a setting for promoting health. British Journal of Sports Medicine 46(1): 4-5.

Dooris M (2006) Healthy settings: Challenges to generating evidence of effectiveness. Health Promotion International 21: 55-65.

Dooris M, Wills J and Newton J (2014) Theorizing healthy settings: A critical discussion with reference to Healthy Universities. Scandinavian Journal of Public Health 42: 7-16.

Duda JL, Quested E, Haug E, et al. (2013) Promoting Adolescent health through an intervention aimed at improving the quality of their participation in Physical Activity (PAPA): Background to the project and main trial protocol. International Journal of Sport and Exercise Psychology 11: 319-327.

Eime RM, Young JA, Harvey JT, et al. (2013) A systematic review of the psychological and social benefits of participation in sport for children and adolescents: Informing development of a conceptual model of health through sport. International Journal of Behavioral Nutrition and Physical Activity 10: 98.

European Commission (2007) White paper: White paper on sport. Available at: https:/eur-lex.europa.eu/ legal-content/EN/TXT/?uri=CELEX\%3A52007DC0391

Geidne S, Kokko S, Lane A, et al. (2019) Health promotion interventions in sports clubs: Can we talk about a setting-based approach? A systematic mapping review. Health Education \& Behavior 46: 592-601. 
Honta M (2016) The state and management of partnership arrangements in France: An analysis of the implementation of the 'Sport, Health and Well-being' plan. International Journal of Sport Policy and Politics 8: $577-591$.

Johnson S, Vuillemin A, Geidne S, et al. (2019) Measuring health promotion in sports club settings: A modified Delphi study. Health Education \& Behavior 29: ckz186.475.

Kokko S (2014a) Guidelines for youth sports clubs to develop, implement, and assess health promotion within its activities. Health Promotion Practice 15: 373-382.

Kokko S (2014b) Sports clubs as settings for health promotion: Fundamentals and an overview to research. Scandinavian Journal of Public Health 42: 60-65.

Kokko S, Green LW and Kannas L (2014) A review of settings-based health promotion with applications to sports clubs. Health Promotion International 29: 494-509.

Kokko S, Kannas L and Villberg J (2009) Health promotion profile of youth sports clubs in Finland: Club officials' and coaches' perceptions. Health Promotion International 24: 26-35.

Kokko S, Martin L, Geidne S, et al. (2019) Does sports club participation contribute to physical activity among children and adolescents? A comparison across six European countries. Scandinavian Journal of Public Health 47: 851-858.

Kokko S, Selänne H, Alanko L, et al. (2015a) Health promotion activities of sports clubs and coaches, and health and health behaviours in youth participating in sports clubs: The Health Promoting Sports Club study. BMJ Open Sport \& Exercise Medicine 1: e000034.

Kokko S, Villberg J and Kannas L (2015b) Health promotion in sport coaching: Coaches and young male athletes' evaluations on the health promotion activity of coaches. International Journal of Sports Science \& Coaching 10: 339-352.

Lee A, Tsang C, Lee S, et al. (2003) A comprehensive 'Healthy Schools Programme' to promote school health: The Hong Kong experience in joining the efforts of health and education sectors. Journal of Epidemiology and Community Health 57: 174-177.

McAuley E, Duncan T and Tammen VV (1989) Psychometric properties of the Intrinsic Motivation Inventory in a competitive sport setting: A confirmatory factor analysis. Research Quarterly for Exercise and Sport 60: 48-58.

Mansfield L, Kay T, Anokye N, et al. (2018) A qualitative investigation of the role of sport coaches in designing and delivering a complex community sport intervention for increasing physical activity and improving health. BMC Public Health 18: 1196.

Marsh HW, Martin AJ and Jackson S (2010) Introducing a short version of the physical self description questionnaire: New strategies, short-form evaluative criteria, and applications of factor analyses. Journal of Sport and Exercise Psychology 32: 438-482.

Meganck J, Scheerder J, Thibaut E, et al. (2015) Youth sports clubs' potential as health-promoting setting: Profiles, motives and barriers. Health Education Journal 74: 531-543.

Meganck J, Seghers J and Scheerder J (2016) Exploring strategies to improve the health promotion orientation of Flemish sports clubs. Health Promotion International 32: 681-690.

Misener L and Misener KE (2016) Examining the integration of sport and health promotion: Partnership or paradox? International Journal of Sport Policy and Politics 8: 695-712.

Oja P, Titze S, Kokko S, et al. (2015) Health benefits of different sport disciplines for adults: Systematic review of observational and intervention studies with meta-analysis. British Journal of Sports Medicine 49: 434-440.

Quested E, Ntoumanis N, Viladrich C, et al. (2013) Intentions to drop-out of youth soccer: A test of the basic needs theory among European youth from five countries. International Journal of Sport and Exercise Psychology 11: 395-407.

Rasbash J, Browne W, Goldstein H, et al. (2000) A User's Guide to Mlwin. London: Centre for Multilevel Modelling, Institute of Education, University of London.

Ryan RM and Frederick C (1997) On energy, personality, and health: Subjective vitality as a dynamic reflection of well-being. Journal of Personality 65: 529-565.

Tabachnick B and Fidell L (2007) Multivariate analysis of variance and covariance. Using Multivariate Statistics 3: 402-407. 
Van de Mortel TF (2008) Faking it: Social desirability response bias in self-report research. Australian Journal of Advanced Nursing 25: 40-48.

Van Hoye A, Fenton S, Krommidas C, et al. (2013) Physical activity and sedentary behaviours among grassroots football players: A comparison across three European countries. International Journal of Sport and Exercise Psychology 11: 341-350.

Van Hoye A, Heuzé J-P, Meganck J, et al. (2018) Coaches' and players' perceptions of health promotion activities in sport clubs. Health Education Journal 77: 169-178.

Van Hoye A, Heuzé J-P, Van den Broucke S, et al. (2016) Are coaches' health promotion activities beneficial for sport participants? A multilevel analysis. Journal of Science and Medicine in Sport 19: 1028-1032.

Van Hoye A, Sarrazin P, Heuzé J-P, et al. (2015) Coaches' perceptions of French sports clubs: Healthpromotion activities, aims and coach motivation. Health Education Journal 74: 231-243.

Wold B, Duda JL, Balaguer I, et al. (2013) Comparing self-reported leisure-time physical activity, subjective health, and life satisfaction among youth soccer players and adolescents in a reference sample. International Journal of Sport and Exercise Psychology 11: 328-340.

World Health Organization (WHO) (1986) Ottawa charter for health promotion: First international conference on health promotion, Ottawa, 21 November 1986. Available at: http://www.who.int/healthpromotion/conferences/previous/ottawa/en/ 